\title{
What Can We Learn by Disaggregating the Unemployment-Vacancy Relationship?
}

\section{Rand Ghayad and William Dickens}

\section{Abstract:}

The Beveridge curve-the empirical relationship between unemployment and job vacancies-is thought to be an indicator of the efficiency of the functioning of the labor market. Normally, when job vacancies rise, unemployment falls, following a curved path that typically remains stable over long periods of time. When vacancies rise and unemployment does not fall (or falls too slowly) this may be an indication of problems of structural mismatch in the labor market leading to an increase in the lowest unemployment rate that can be maintained without increasing inflation (the NAIRU or nonaccelerating inflation rate of unemployment). Such a change in the vacancy-unemployment relationship occurred once in the 1970s and persisted through the late 1980s, and we have recently observed a similar change.

This policy brief explores the nature of the recent change in the vacancy-unemployment relationship by disaggregating the data by industry, age, education, and duration of unemployment, and by examining blueand white-collar groups separately.

The plots presented here reveal a similar pattern of increasing vacancies with little or no change in unemployment in the recovery from the most recent recession across all categories except one: short-term unemployment. The relationship between short-term unemployment and vacancies is unchanged. Thus, all of the increase in vacancies relative to unemployment has taken place among the long-term unemployed.

This situation contrasts with the change in the Beveridge curve relationship in the 1970s, when an increase in the level of vacancies without a decline in unemployment affected both the long- and short-term unemployed. Further, in the 1970s the outward shift of the Beveridge curve was largely concentrated among blue-collar workers, whereas the recent shift seems to have affected both blue- and white-collar workers. Finally, the shift in the 1970s took place over several years, while the current shift seems to have taken less than six months. Thus, there is reason to believe that the current shift may not have the persistence or the effects on the NAIRU that the shift of the 1970s had.

Considering all the evidence together, we conclude that the current outward shift of the Beveridge curve is likely being driven by something other than a mismatch between workers' skills and the demands of available jobs.

\section{JEL Codes: D31, D63, I32}

Rand Ghayed is a Ph.D. candidate at Northeastern University and a visiting graduate fellow at the Federal Reserve Bank of Boston. William Dickens is a university distinguished professor at Northeastern University, a visiting scholar at the Federal Reserve Bank of Boston, and a nonresident senior fellow with the Brookings Institution. Their e-mail addresses are ghayad.r@husky.neu.edu and wtdickens@gmail.com, respectively.

The views expressed in this brief are the authors' and do not necessarily reflect the official position of the Federal Reserve Bank of Boston or the Federal Reserve System.

This brief, which may be revised, is available on the web site of the Federal Reserve Bank of Boston at http://www.bostonfed.org/economic/ppb/index.htm.

This version: October 2012 
Although the U.S. economy has been recovering slowly since the last quarter of 2009, the unemployment rate has remained stubbornly high. The persistence of high unemployment is particularly puzzling, given that the number of job openings has been rising during the same period.

Figure 1 plots vacancy-unemployment points from 2001 on. The curved relationship between unemployment and job vacancies depicted in Figure 1 is often called the Beveridge curve. Over the recession of the early 2000s and the recovery from that recession, the vacancy-unemployment relationship remained remarkably constant as it has for long periods of time in the past. However, in the recovery from the most recent recession we see that vacancies have grown considerably without producing the normal decline in unemployment. It appears that the Beveridge curve may have shifted outward.

There is one time in the past when the relationship shifted outward in a similar manner. During the 1970s, vacancies rose without a normal drop in unemployment, and the Beveridge curve shifted outward for much of the 1980s. During that period of time it was thought that the labor market was doing a worse job than usual of matching workers and jobs, resulting in a higher NAIRU (nonaccelerating inflation rate of unemployment). Are similar forces at work now?

This brief uncovers new facts that emerge from disaggregating the unemployment rate into various categories. The insights from these disaggregations may reveal new information on whether the breakdown of the vacancy-unemployment relationship today is similar to the change that took place in the 1970s and may provide some insight as to the likely cause of the recent change.

Figure 1 displays an empirical relationship between data on vacancies from the Job Openings and Labor Turnover Survey (JOLTS) of the Bureau of Labor Statistics (BLS) and the aggregate unemployment rate obtained from the monthly household survey, also from the BLS. The data span the period January 2001 through June 2012 and are seasonally adjusted. The solid line in Figure 1 depicts a stylized Beveridge curve that was estimated using data on unemployment and vacancy rates for the period prior to the start of the recession. The plot reveals that by September 2009, the vacancy-unemployment points started to deviate from the fitted curve in a counterclockwise direction, indicating a higher unemployment rate at any given level of job openings.

One notable difference between the experience this time and what happened in the 1970s is the rapidity with which this change took place. In the 1970s it took eight years for the outward shift to take place (see Figure 10). The recent shift (about half the size of the shift in the 1970s) took less than a year, with most of the change taking place in the last six months of 2009.

Another notable difference between the current period and the 1970s is the very high level of long-term unemployment. Figure 2 shows the proportion of total unemployed who have been out of work for at least six months.

It is interesting that the Beveridge curve starts shifting outward only after long-term unemployment reaches its peak level. We will have more to say about this in the conclusion, but the emergence of the long-term unemployed as a large fraction of the unemployed motivates the first break-down that we look at-the Beveridge curve at different durations of unemployment. 


\section{Total Vacancies and Unemployment Rates by Duration of Unemployment}

We disaggregate the seasonally adjusted BLS series of monthly unemployment rates for all employees 16 years of age and over to examine the vacancy-unemployment relationship at different durations of unemployment in order to see whether the unemployed for different durations benefit differently from the recent increase in the vacancy rate. We plot the aggregate vacancy rate, using data from JOLTS, against the fraction of the labor force unemployed at different durations. Figure 3 presents this relationship for those unemployed for less than five weeks.

The relationship between the vacancy rate and the very short-run (less than five weeks) unemployment rate is essentially vertical-around 2 percent of the labor force is in the first five weeks of a spell of unemployment, regardless of the level of job vacancies. There does not appear to have been any change in the relationship in 2009. Hence, evidence from the experience of individuals with unemployment spells shorter than five weeks does not explain what we see in the aggregate plot.

Figures 4 and 5 illustrate vacancy-unemployment relationships using unemployed persons with duration 5-14 weeks and 15-26 weeks, respectively. Figure 6 combines all those unemployed for fewer than 27 weeks and compares their fraction of the labor force with the aggregate vacancy rate.

As with the graphs for each of these durations individually, there is no evidence of an outward shift. However, when the relationship is plotted using the fraction of the labor force that has been unemployed for more than 26 weeks, a number of interesting features are immediately apparent. First, the pattern in Figure 7 reveals a counterclockwise outward shift that is consistent with what we see when we use the aggregate unemployment rate. In addition to the shift, the pattern in Figure 7 shows that the vacancy and unemployment points for the long-term unemployment group start to shift outward at the same time as the aggregate vacancyunemployment relationship breaks down.

Looking at how events have unfolded over time, we see in Figure 8 that the vacancy-unemployment points for the short-term unemployment group cycle inward in a clockwise pattern, while those for the long-term unemployment group move in an outward, counter-clockwise manner. At the aggregate level, counterclockwise movements are common to all recessions because vacancies typically adjust before unemployment to changes in labor demand. The different dynamics of the short- and long-term unemployment-vacancy relationships suggest that the short-term unemployed benefit from the increase in the vacancy rate far more than the long-term unemployed do.

\section{What Happened in the 'Seventies at Different Durations?}

How does the recent change in the vacancy-unemployment relationship compare with what happened in the 1970s? As noted above, the recent increase happened much more quickly than the one in the 1970s, casting doubt on the hypothesis that they share similar origins. Examination of changes at the disaggregated level suggests another reason to doubt similar origins.

Figure 9 shows the vacancy-unemployment relationship using all unemployment groups for the period from January 1960 to December 1988. The Conference Board's help wanted index is used to construct the vacancy 
rate, using the method suggested by Zargosky (1998). The plot clearly shows an outward shift of the Beveridge curve.

Examining the Beveridge curves for the short- and long-term unemployment groups plotted with data covering the 1960-1988 period, we notice that both curves shifted outward at the same time as the start of the outward movement of the aggregate curve (Figures 10-11). This contrasts with the current period, in which the breakdown in the vacancy-unemployment relationship is evident only for the long-term unemployed.

\section{Other Decompositions}

Do other ways of disaggregating reveal any other places where the shift in the vacancy-unemployment rate is concentrated or missing? Below we disaggregate by industry, age, education, and blue- versus white-collar workers.

\section{Vacancy and Unemployment Rates by Industry}

The section below presents vacancy-unemployment relationships for six major industries to examine whether the outward shift that we see in the aggregate data has been equally pronounced across all sectors of the economy. Each plot of Figures 12-17 illustrates the relationship between the unemployment rate and the vacancy rate in a particular industry for the period spanning January 2001 to June 2012.

Seasonally adjusted data by industry for vacancy and unemployment rates were collected from the JOLTS and the BLS, respectively and grouped into six major categories covering construction, financial activities, trade/transportation/utilities, professional business services, leisure/hospitality, and education/health services. Note that these plots differ from previous plots in that sector-specific, rather than the aggregate, vacancy rates are used. Also, to be classified as unemployed in an industry by the Bureau of Labor Statistics, a worker's last job must have been in that industry.

The plots show a breakdown in the vacancy-unemployment relationship across all industries at the time the aggregate Beveridge curve was moving outward.

\section{Vacancy and Unemployment Rates by Age}

Decomposing the unemployed into different age categories and plotting the aggregate vacancy rate versus the unemployment rate of different age groups (Figures 19-21) also reveals outward shifts across all categories. The shifts are consistent with the pattern observed using aggregate data on unemployment and vacancies and suggest that the outward shift is common to all age groups.

\section{Vacancy and Unemployment Rates by Education}

Looking at the relationship between the aggregate vacancy rate and the unemployment rate broken down by education rates, the plots (Figures 22-24) show a similar pattern in which outward shifts in each educational category occur simultaneously with the aggregate Beveridge curve shifting outward. 


\section{Vacancy and Unemployment Rates for Blue- and White-Collar Workers}

Here, we examine the vacancy-unemployment relationship for blue-collar workers (manufacturing and production workers, laborers and helpers, construction crafts, and transportation operatives) and white-collar workers (all others). Similar to the other breakdowns, we see a shift outward for both blue- and white-collar workers (Figures 25-26).

It is interesting to note that the pattern in the current recession is different from the outward shift in the Beveridge curve in the 1973-to-1985 period. At that time there was little, if any, shift in the Beveridge curve for white-collar workers, but a large shift for blue-collar workers (Figure 27).

\section{Conclusion}

Disaggregating the vacancy-unemployment relationship reveals some interesting new facts that may shed light on the implications of what appears to be an outward shift of the Beveridge curve in recent years.

While the Beveridge curve for all workers appears to have shifted outward starting in 2009, data on vacancy and unemployment rates for individuals who have been unemployed for fewer than 27 weeks reveal the usual downward-sloping relationship with no sign of any outward shift. Interestingly, a dynamic plot of the vacancy rate versus the short-term unemployment rate shows clockwise cycling of the vacancy-unemployment points for the unemployed. In contrast, we see a large counterclockwise movement when the vacancy rate is plotted versus the unemployment rate for those unemployed for more than 26 weeks. Taken together, these observations suggest that the short-term unemployed have been benefiting more than the long-term unemployed from increases in vacancies during the recovery.

It is widely thought that the outward shift in the Beveridge curve in the 1970s reflected a worsening of matching efficiency - that it was hard to get suitable workers and jobs together-and that this worsened the overall unemployment rate. We observe three differences between what happened in the 1970s and today's changes. First, the outward shift happened much more quickly in the recent period than in the 1970s, taking months rather than years. Second, in the 1970s the outward shift was common to all durations of unemployment, as we would expect from a general decline in the efficiency of matching. In contrast, the current change has taken place only among the very-long-term unemployed, with some evidence of a slight improvement in the tradeoff for the short-term unemployed. Finally, the outward shift in the 1970s was concentrated among blue-collar workers. Again, this is what we might expect if shifting industry composition were creating a greater mismatch of skills (we might expect white-collar skills to be more portable between industries). In the current period we see that the worsening tradeoff between vacancies and unemployment is common to both blue- and white-collar workers.

Other than the contrast between the long and short-term unemployed, the break-down in the vacancyunemployment relationship in the recent period seems to have occurred across all industries, education levels, age groups, and among both blue- and white-collar workers.

Any explanation of the change in the vacancy-unemployment relationship has to account for its pervasiveness across industry groups, blue-white collar occupations, age and education groups, concentration among the long-term unemployed, and absence from the short-term relationship. 
One reason why the Beveridge curve relationship for the long-term unemployed has apparently shifted may be a change in the desirability of the long-term unemployed to employers. It is possible that the long-term unemployed increasingly comprise workers whose skills are not suited to available jobs. However, if this is the case why do we not see some outward shift in the short-term relationship as well? Further, the mismatch hypothesis is called into question by the fact that the vacancy-unemployment relationship has shifted in all industries, while in the 1970s only the workers who were previously employed in blue-collar industries were affected. Another possibility is that the long-term unemployed in this recession may be searching less intensively - either because jobs are much harder to find or because of the availability of unprecedented amounts and durations of unemployment benefits. This seems to be a more likely explanation, although if a drop in search intensity is due only to the difficulty of finding jobs, it again raises the question why we would not see that phenomenon at shorter durations as well. 
Figure 1: Monthly Vacancy and Unemployment Rates, Jan 2001 to Jun 2012

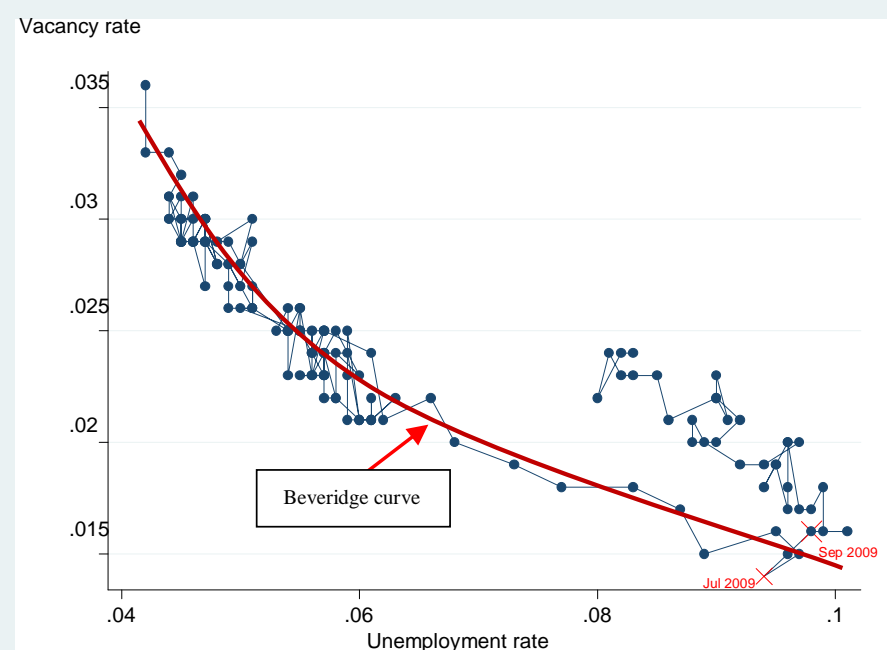

Source: CPS and JOLTS. Data are monthly and seasonally adjusted

Figure 3: Monthly Vacancy and Unemployment Rates, Using Unemployed Persons with Duration Less Than 5 Weeks

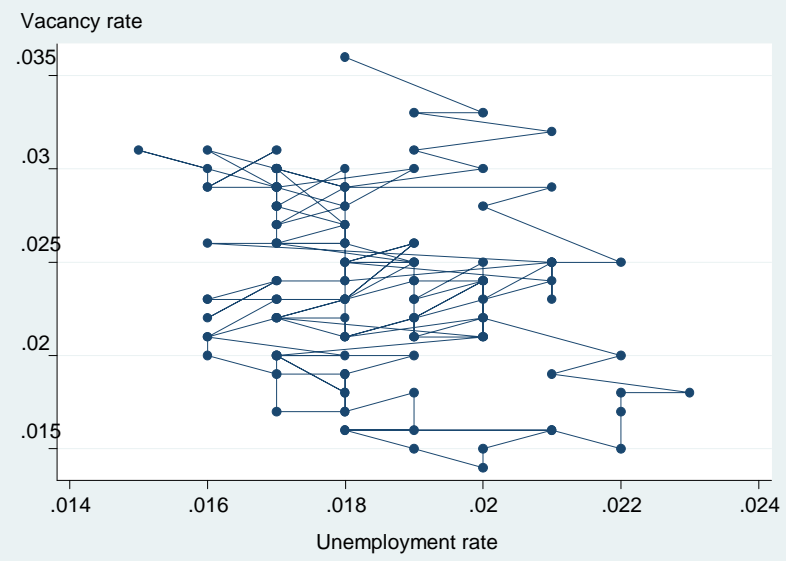

Source: CPS and JOLTS. Data are monthly rates, span the period 2001:m1- 2012:m6, and are seasonally adjusted.
Figure 2: Proportion of Unemployed Who Have Been Unemployed for More Than 26 weeks

Percent Long-term unemployed

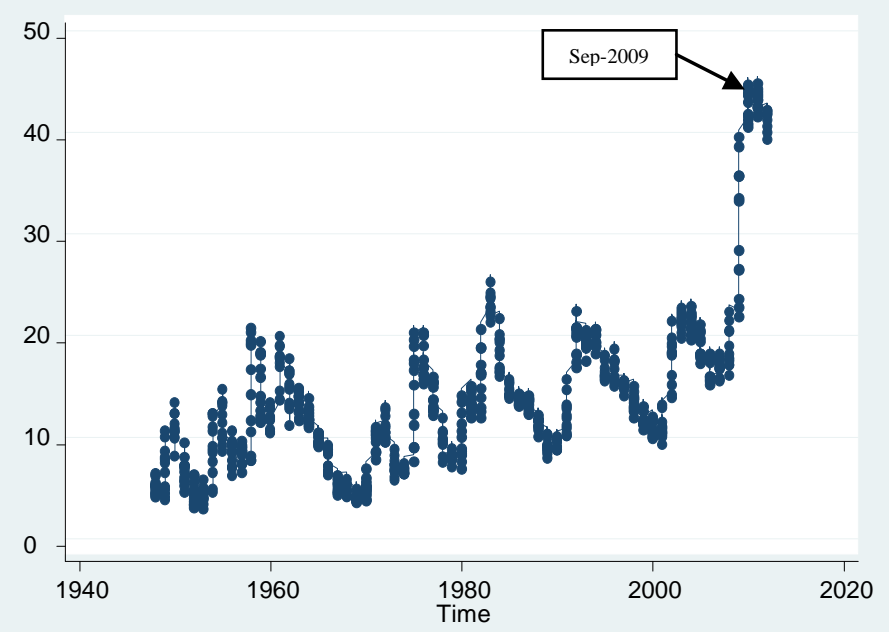

Source: CPS and JOLTS. Data are monthly rates, span the period 2001:m1-2012:m6, and are seasonally adjusted.

Figure 4: Monthly Vacancy and Unemployment Rates Using Unemployed Persons with Duration of 5-14 Weeks

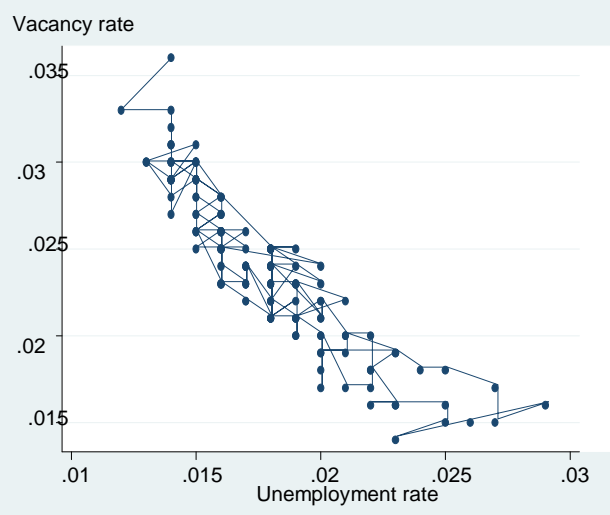

Source: CPS and JOLTS. Data are monthly rates, span the period 2001:m1- 2012-m6, and are seasonally adjusted. 
Figure 5: Monthly Vacancy and Unemployment Rates Using Unemployed Persons with Duration of 15-26 Weeks

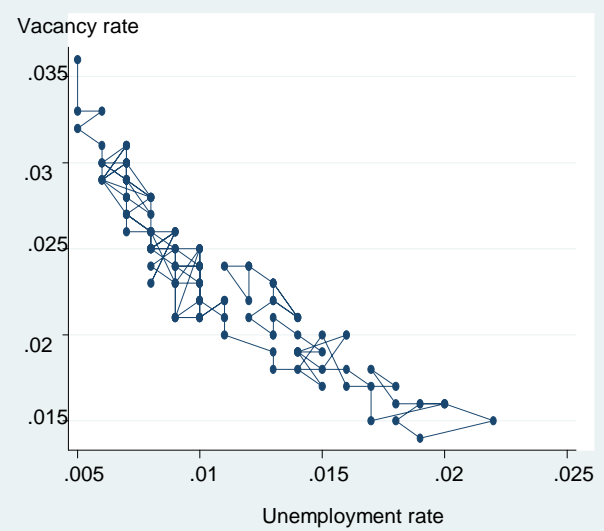

Source: CPS and JOLTS. Data are monthly rates, span the period 2001:m1-2012:06, and are seasonally adjusted.
Figure 6: Monthly Vacancy and Unemployment Rates Using Unemployed Persons with Duration Less Than 27 Weeks

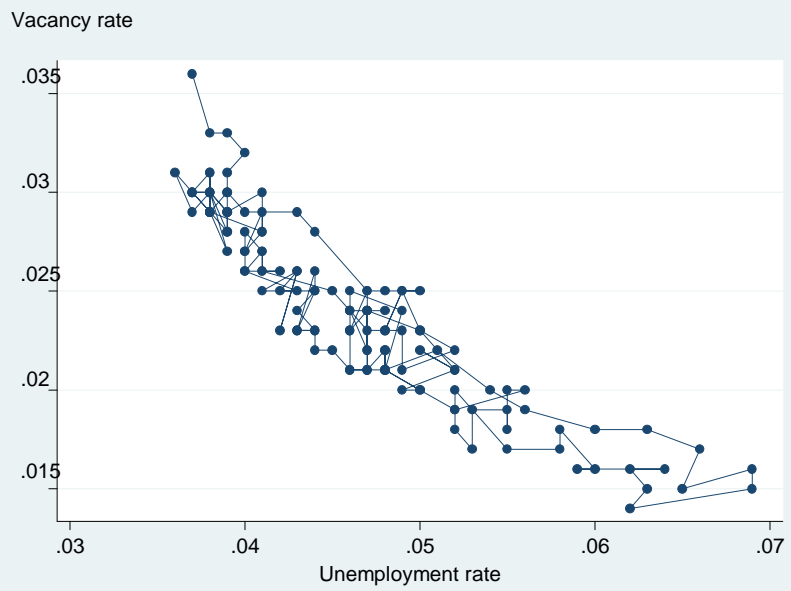

Source: CPS and JOLTS. Data are monthly rates, span the period 2001:m12012:m6, and are seasonally adjusted.
Figure 7: Monthly Vacancy and Unemployment Rates Using Unemployed Persons with Duration Greater Than or Equal to 27 Weeks

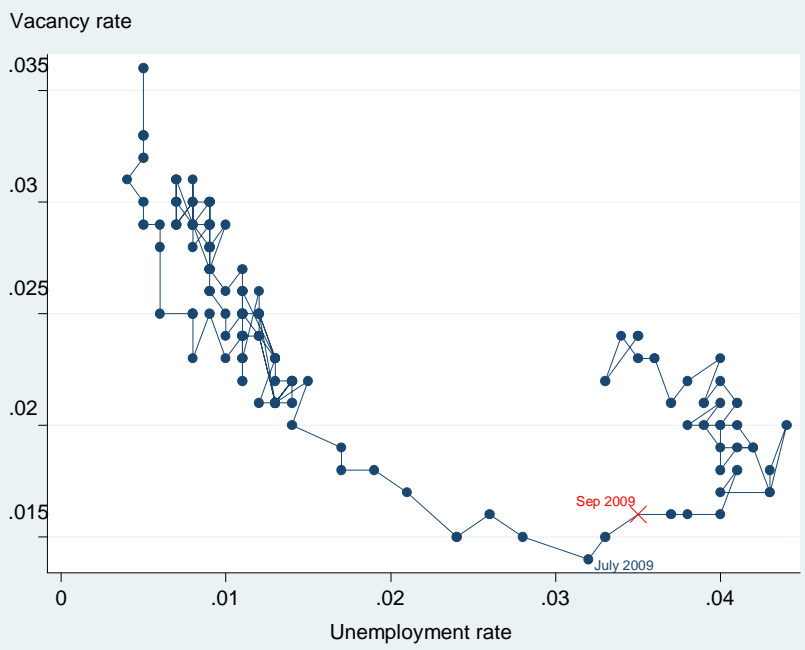

Source: CPS and JOLTS. Data are monthly rates, span the period 2001:m1-2012:m6, and are seasonally adjusted.
Figure 8: Dynamic Plot of Vacancy \& Unemployment Rates for Short-Term and Long-Term Unemployment Groups

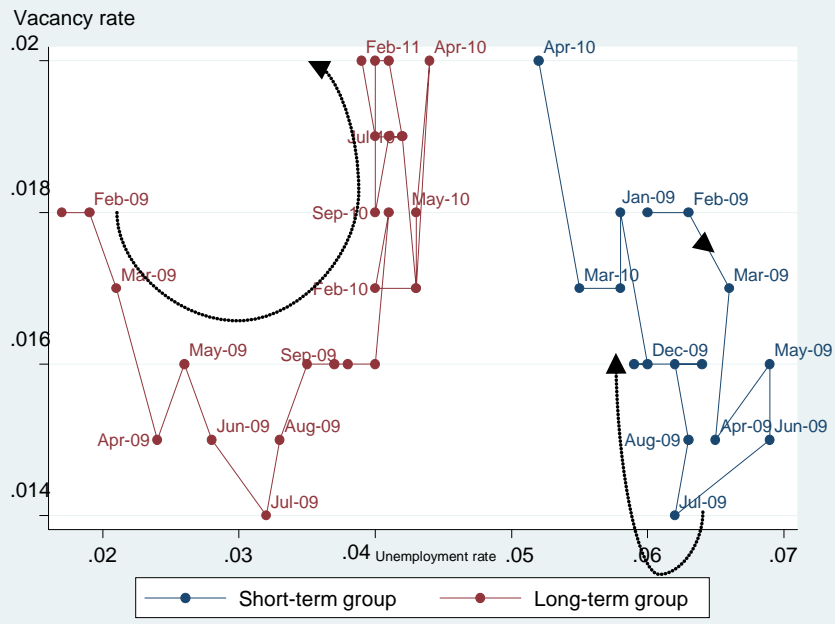

Source: CPS and JOLTS. Data are monthly rates, span the period 2009:m1-2010:m12, and are seasonally adjusted. 
Figure 9: Evolution of the Beveridge Curve During 1960-1988

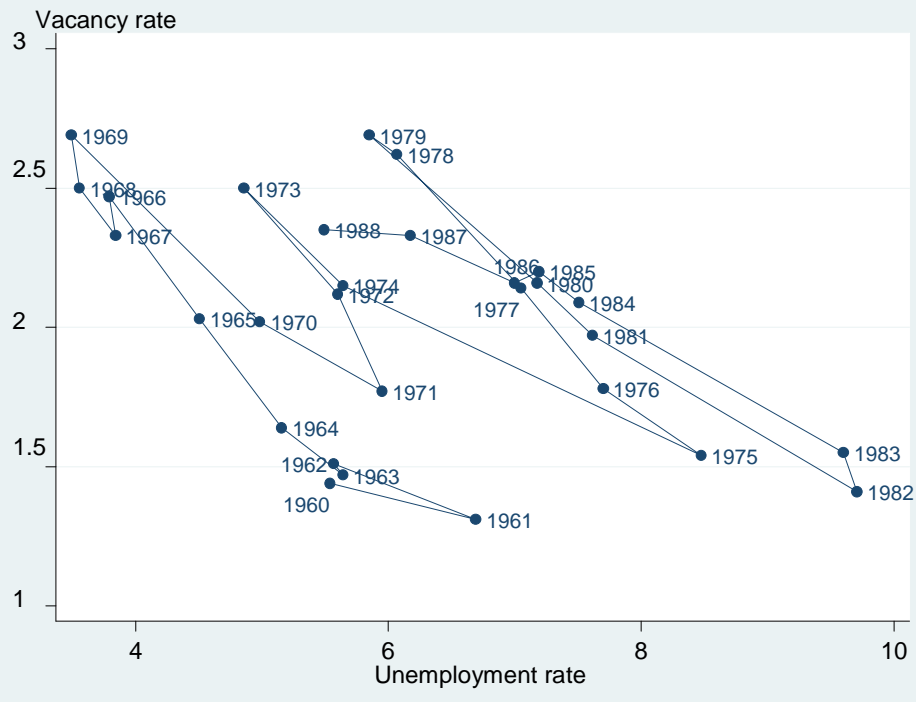

Source: CPS, Conference Board, and authors' calculations. Data are annual averages and span the period 1960-1988.

Figure 11: 1960-1988 Beveridge Curve Using Persons with Unemployment Duration Greater Than or Equal to 27 Weeks

\section{Vacancy rate}

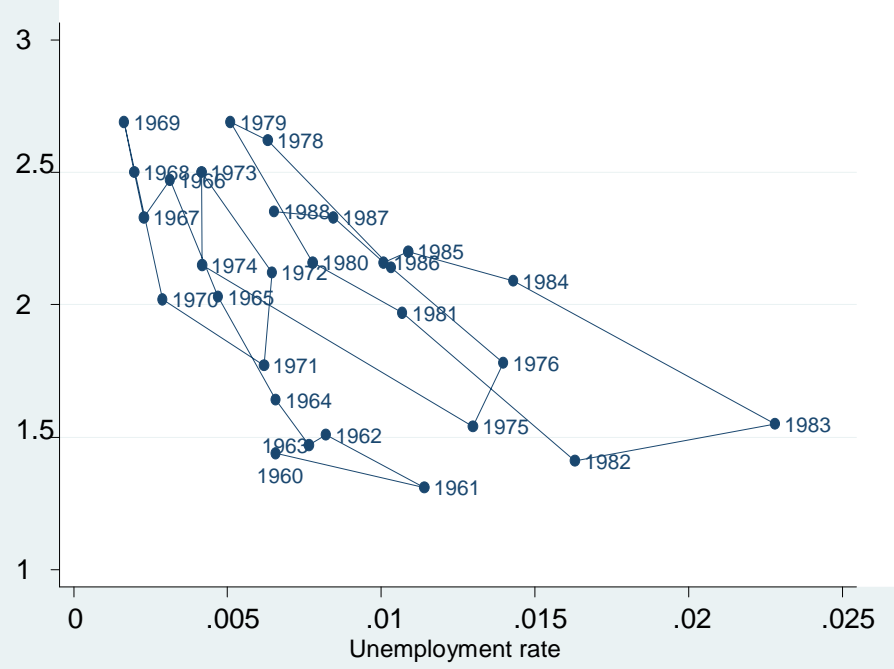

Source: CPS, Conference Board, and authors' calculations. Data are annual rates and span the period 1960-1988.
Figure 10: 1960-1988 Beveridge Curve Using Persons with Unemployment Duration Less Than 27 Weeks

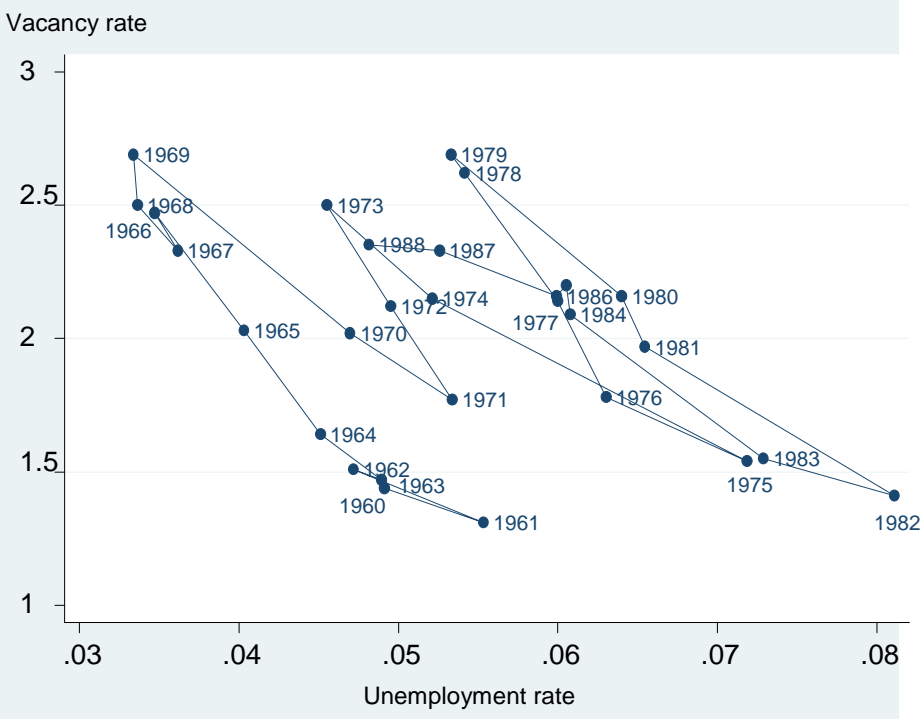

Source: CPS, Conference, and authors' calculations. Data are annual rates and span the period 1960-1988.

Figure 12: Vacancy Rate versus Unemployment Rate in the Construction Industry

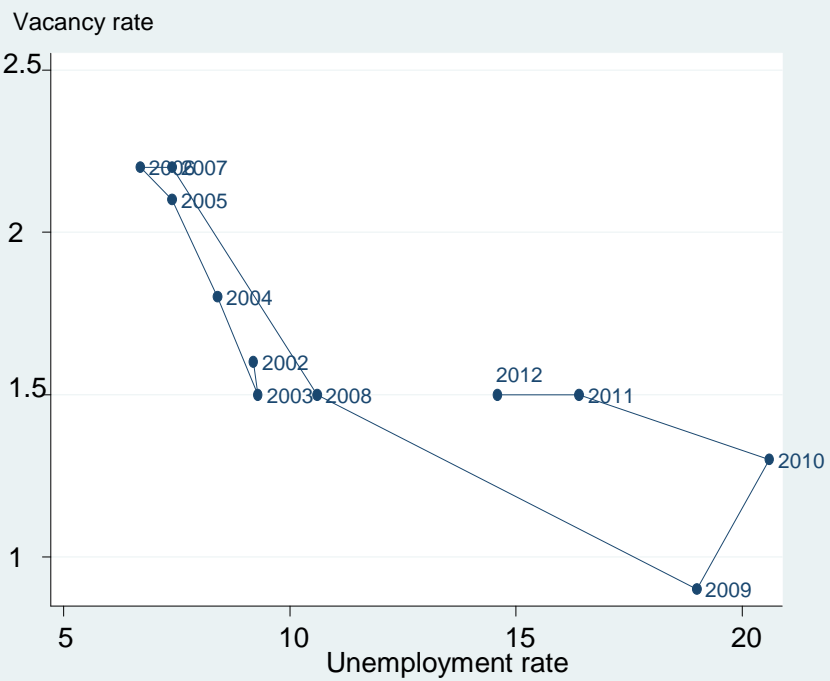

Source: CPS and JOLTS. Vacancy and unemployment rates are annual averages that are specific to the construction industry. They span the period Jan 2002- July 2012. 
Figure 13: Vacancy Rate versus Unemployment Rate in the Financial Services Industry

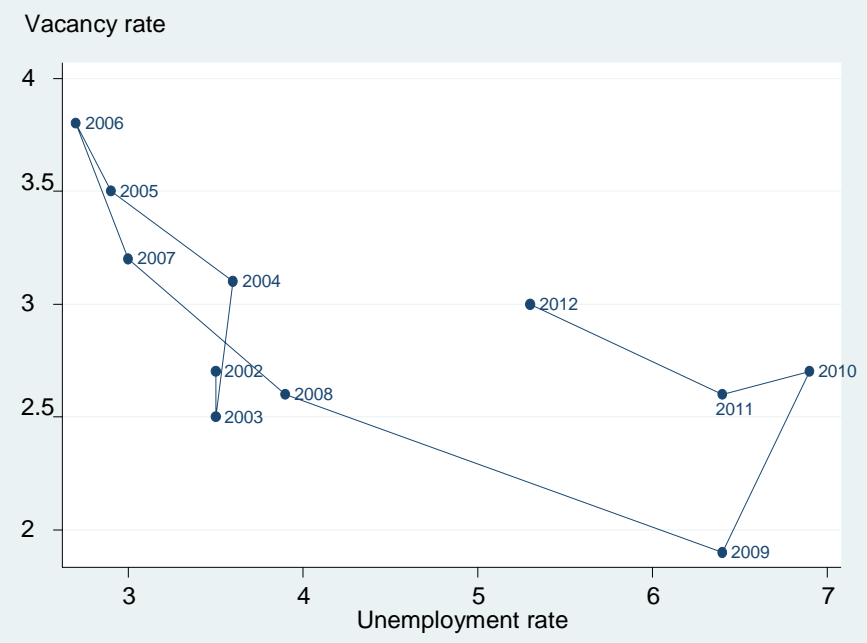

Source: CPS and JOLTS. Vacancy and unemployment rates are annual averages that are specific to the financial services industry. They span the period Jan 2002-July 2012.

Figure 15: Vacancy Rate versus Unemployment Rate in the Professional \& Business Services Industry

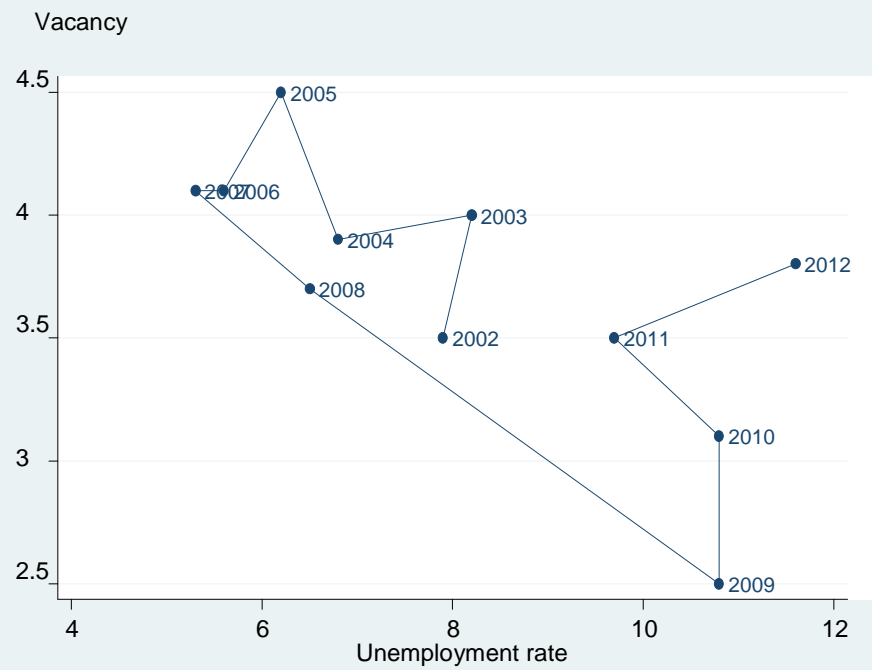

Source: CPS and JOLTS. Vacancy and unemployment rates are annual averages that are specific to the professional \& business services industry. They span the period Jan 2002-July 2012.
Figure 14: Vacancy rate versus Unemployment Rate in the Trade, Transportation \& Utilities industry

Vacancy rate

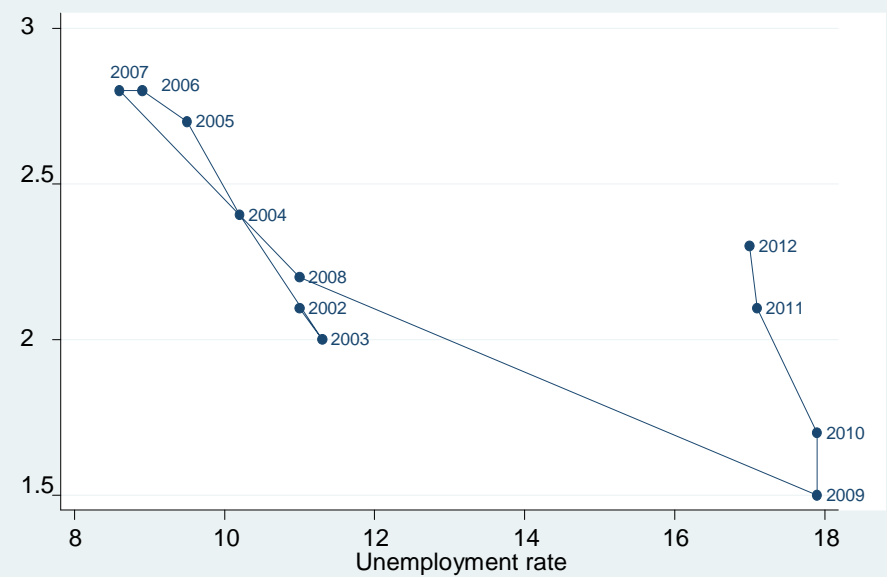

Source: CPS and JOLTS. Vacancy and unemployment rates are annual averages that are specific to the trade, transportation \& utilities industry. They span the period Jan 2002-July 2012.

Figure 16: Vacancy Rate versus Unemployment Rate in the Leisure \& Hospitality Industry

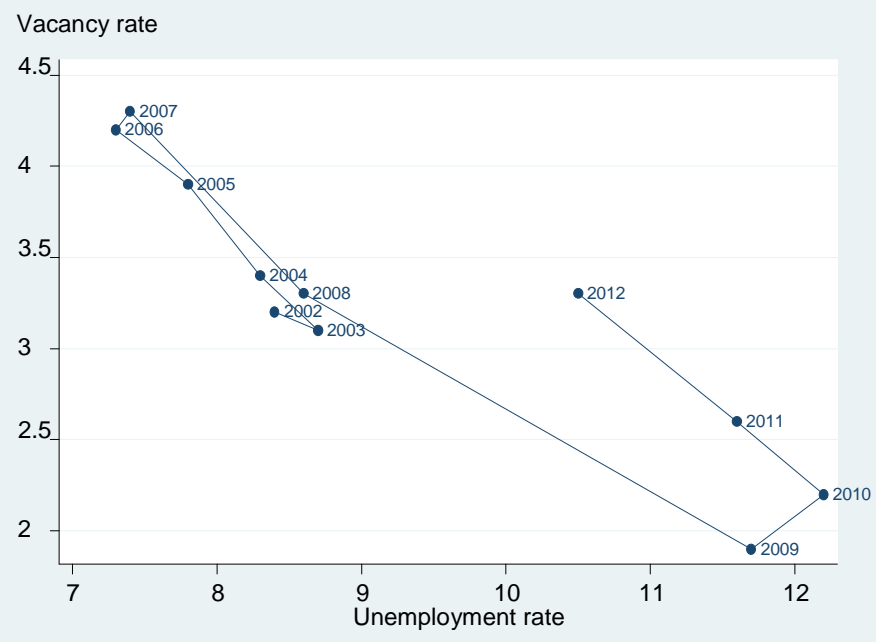

Source: CPS and JOLTS. Vacancy and unemployment rates are annual averages that are specific to the Leisure \& Hospitality industry. They span the period Jan 2002- July 2012. 
Figure 17: Vacancy Rate versus Unemployment Rate in the Education \& Health Services Industry

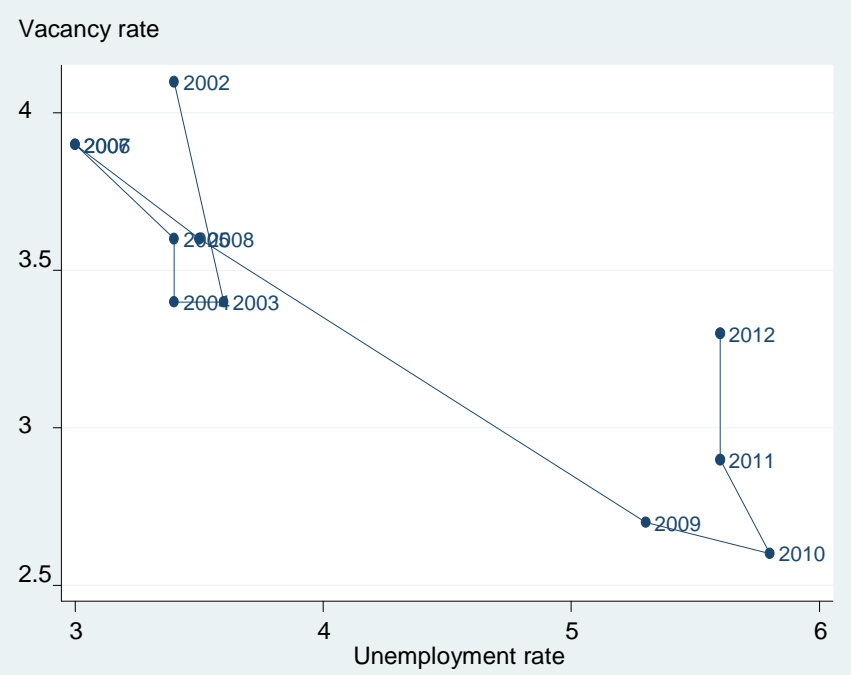

Source: CPS and JOLTS. Vacancy and unemployment rates are annual averages that are specific to the Education \& Health Services industry. They span the period Jan 2002- July 2012.

Figure 19: Monthly Vacancy and Unemployment Rates Plot Using Age Group 25-34 Years

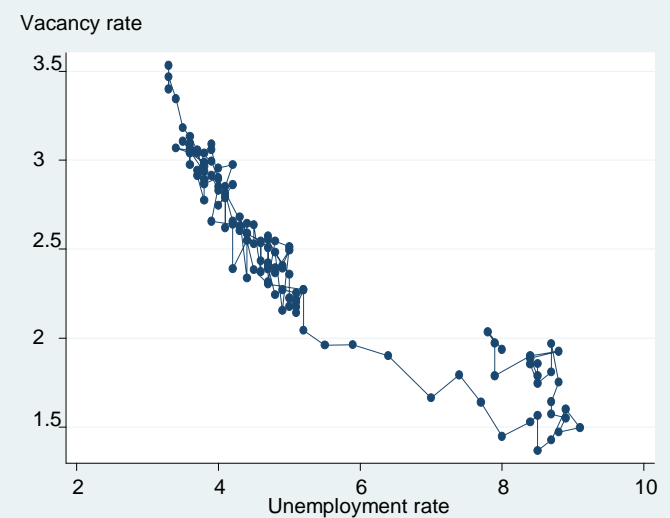

Source: CPS and JOLTS. Data are monthly rates, span the period 2001:m1-2012:m6, and are seasonally adjusted.
Figure 18: Monthly Vacancy and Unemployment Rates Plot Using Age Group 20-24 Years

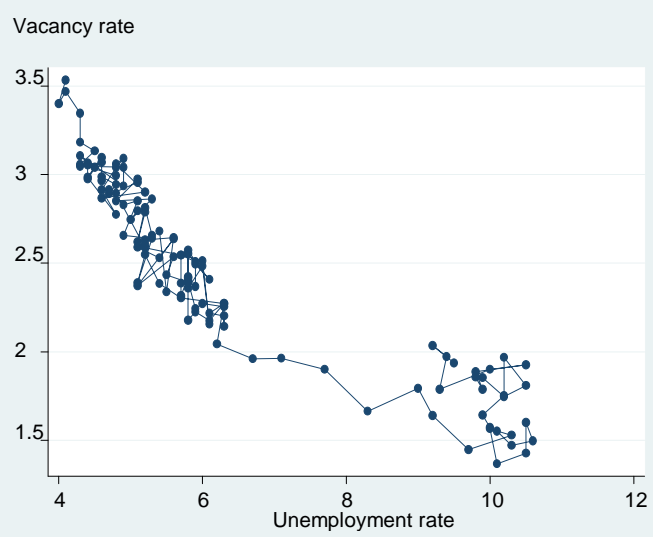

Source: CPS and JOLTS. Data are monthly rates, span the period 2001:m1-2012:06 and are seasonally adjusted.

Figure 20: Monthly Vacancy and Unemployment Rates Plot Using Age Group 25-54 Years

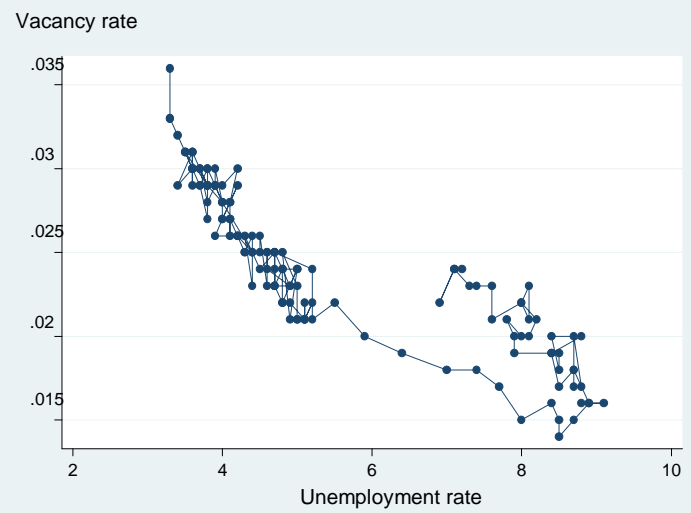

Source: CPS and JOLTS. Data are monthly rates, span the period 2001:m1-2012:m6 and are seasonally adjusted. 
Figure 21: Monthly Vacancy and Unemployment Rates Plot Using Age Group $55+$

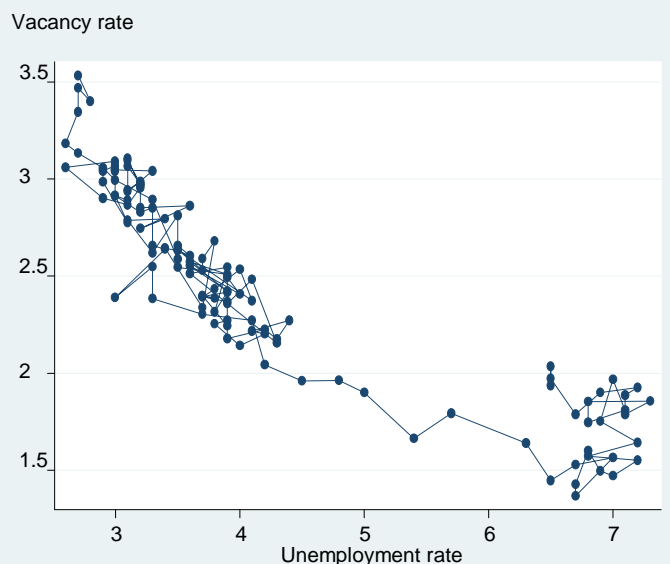

Source: CPS and JOLTS. Data are monthly rates, span the period 2001:m12012:m6, and are seasonally adjusted.

Figure 23: Monthly Vacancy and Unemployment Rates Plot for Unemployed Persons with a High School Degree

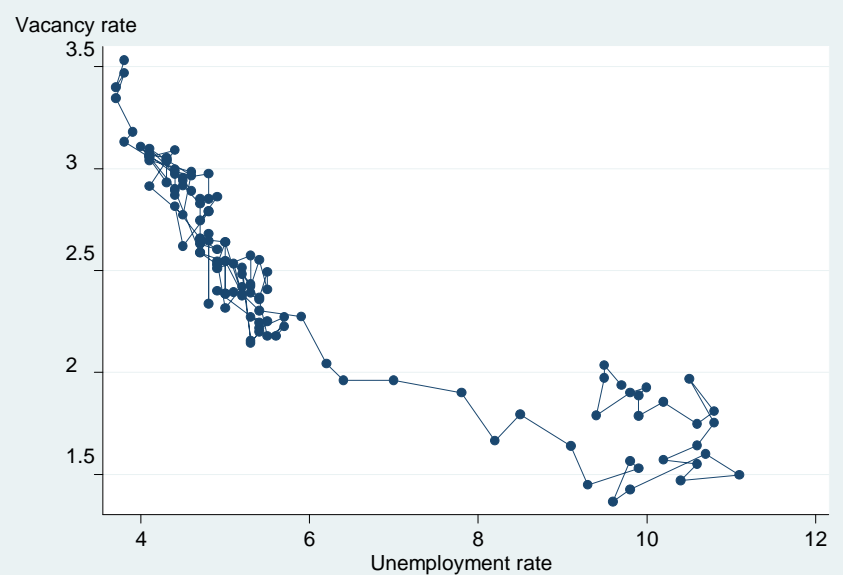

Source: CPS and JOLTS. Data are seasonally adjusted and span the period 2001:m12012:m6. Note: JOLTS does not report data on job openings by education.
Figure 22: Monthly Vacancy and Unemployment Rates Plot for Unemployed Persons with Less than a High School Degree

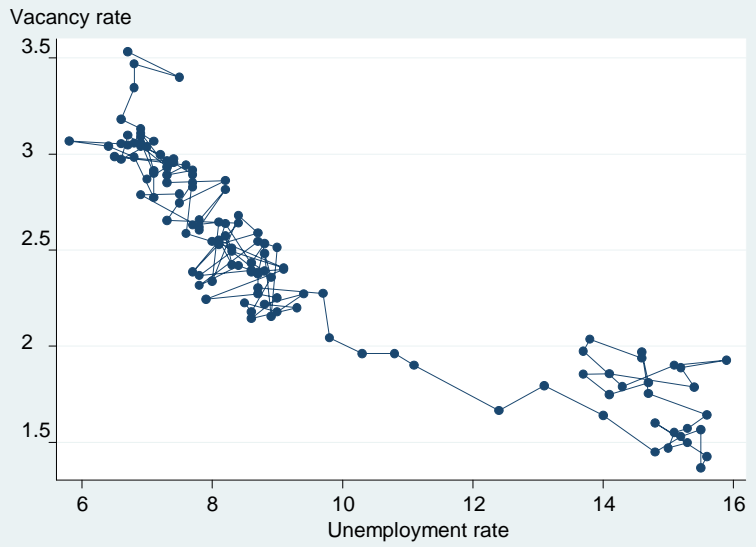

Source: CPS and JOLTS. Data are seasonally adjusted and span the period 2001:m12012:m6. Note: JOLTS does not report data on job openings by education.

Figure 24: Monthly Vacancy and Unemployment Rates Plot for Unemployed Persons with a Bachelor’s Degree

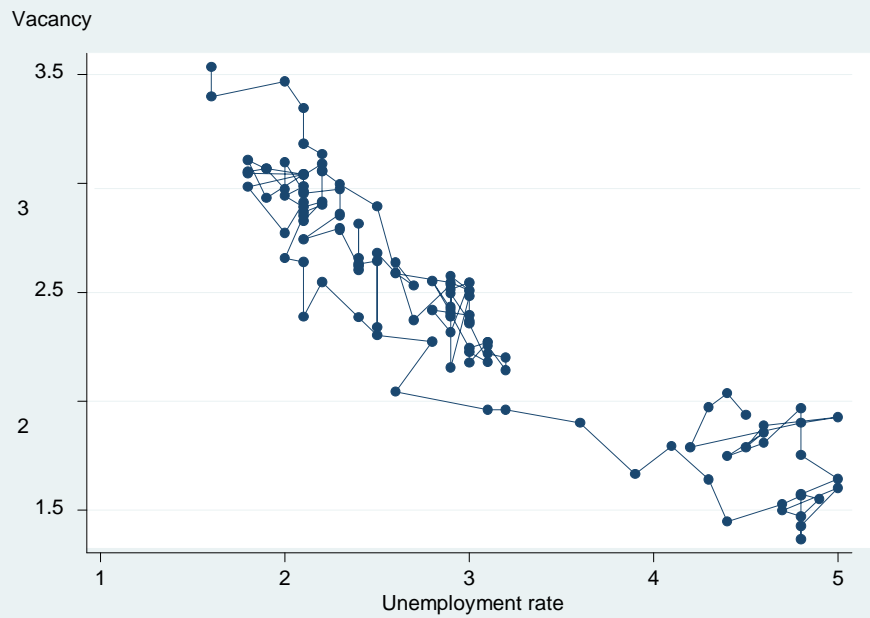

Source: CPS and JOLTS. Data are seasonally adjusted and span the period 2001:m12012:m6. Note: JOLTS does not report data on job openings by education. 
Figure 25: Monthly Vacancy and Unemployment Rates Plot Using Proportion of Blue-Collar Unemployed Workers

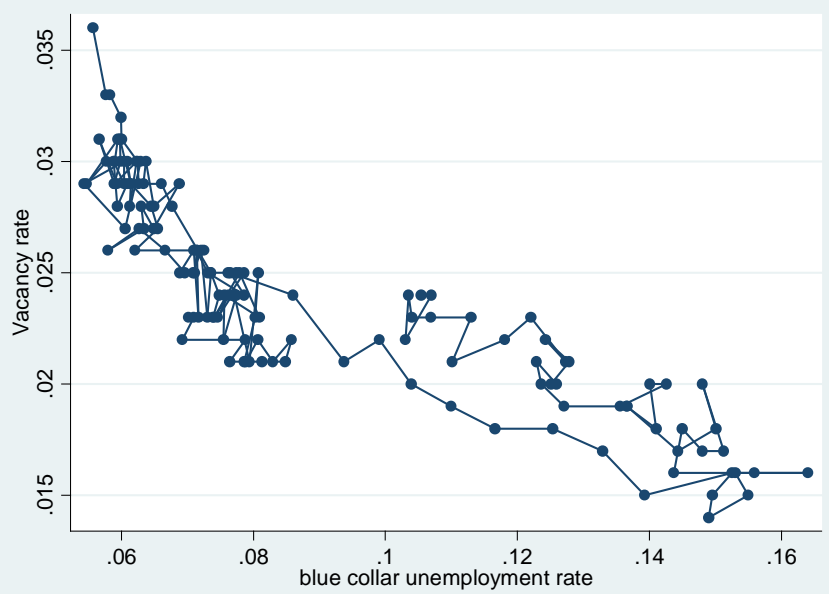

Source: Data on unemployment rate by job category (for blue collar occupations) are obtained from the public data series of the BLS's Current Population Survey. Aggregate vacancy rate data are from the BLS's Jobs Opening and Labor Turnover Survey.

Data are seasonally adjusted and span the period 2001:m1-2012:m9.
Figure 26: Monthly Vacancy and Unemployment Rates Plot Using Proportion of White-Collar Unemployed Workers

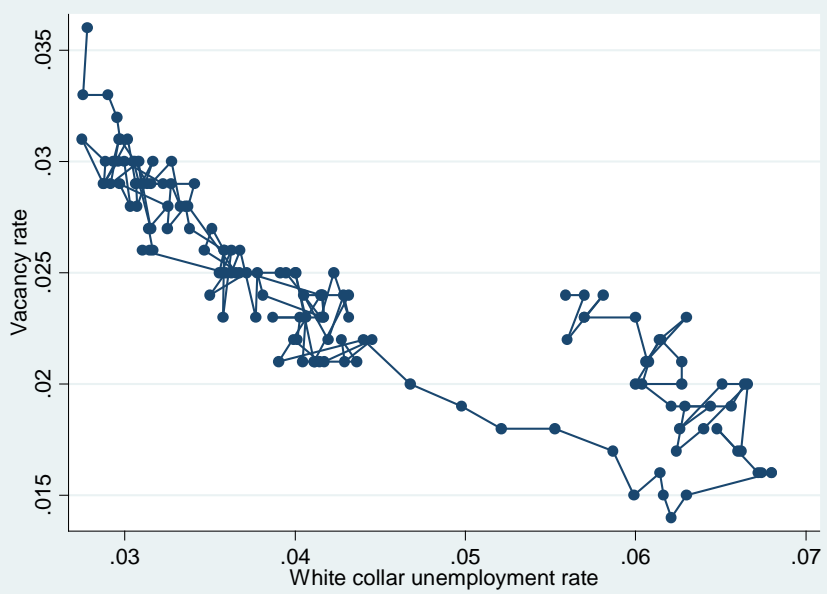

Source: Data on unemployment rate by job category (for white collar occupations) are obtained from the public data series of the BLS's Current Population Survey. Aggregate vacancy rate data are from the BLS's Jobs Opening and Labor Turnover Survey. Data are seasonally adjusted and span the period 2001:m1-2012:m9.
Figure 27: Annual Vacancy and Unemployment Rates for Blue- and White-Collar Workers During 1973-1985

\section{Vacancy rate}

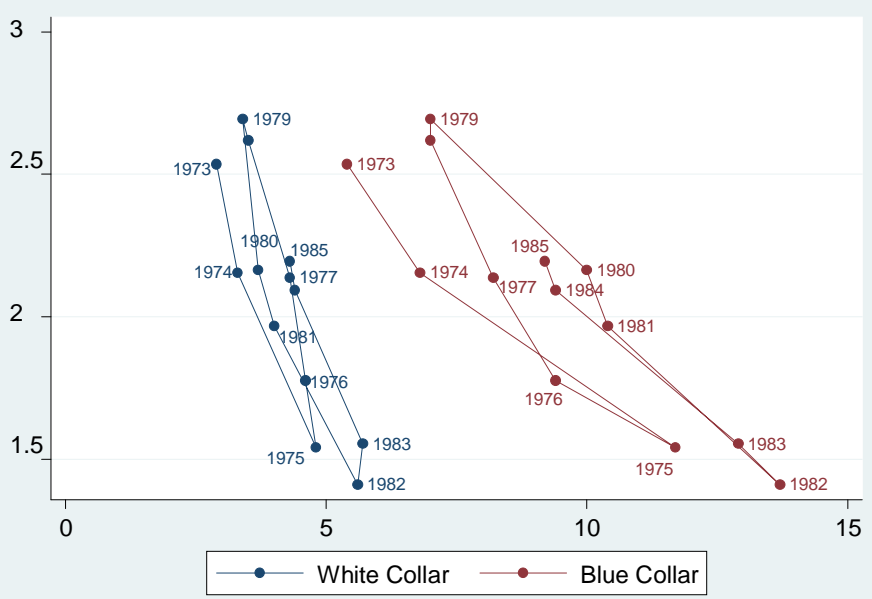

Source: Data on unemployment rate by job category (for blue and white collar occupations) are obtained from the public data series of the BLS's Current Population Survey. Aggregate vacancy rate data are from the BLS's Jobs Opening and Labor Turnover Survey. Note: We use annual rate to smooth high frequency variation in the data. Data are seasonally adjusted and span the period 1973:m1-1985:m12. 